\title{
Chemical Stability of New Acyclovir Analogues with Peptidomimetics
}

\author{
Georgi HRISTOV, Ivanka StANKova *
}

Department of Chemistry, South-West University 'Neofit Rilski', Ivan Michailov str. 66, 2700 Blagoevgrad, Bulgaria.

* Corresponding author. E-mail: ivastankova@abv.bg (I. Stankova)

Sci Pharm. 2011; 79: 259-264

doi:10.3797/scipharm.1012-20

Published: $\quad$ March $5^{\text {th }} 2011$

Accepted: $\quad$ March $3^{\text {rd }} 2011$

Received: $\quad$ December $20^{\text {th }} 2010$

This article is available from: http://dx.doi.org/10.3797/scipharm.1012-20

(c) Hristov and Stankova; licensee Österreichische Apotheker-Verlagsgesellschaft m. b. H., Vienna, Austria.

This is an Open Access article distributed under the terms of the Creative Commons Attribution License (http://creativecommons.org/licenses/by/3.0/), which permits unrestricted use, distribution, and reproduction in any medium, provided the original work is properly cited.

\begin{abstract}
In the search for new and effective prodrugs against the herpes simplex virus, a series of acyclovir analogues with a thiazole ring containing amino acids (glycine, alanine, valine, leucine) has been investigated. The chemical stability of some of the compounds containing different residues was studied at $\mathrm{pH} 1$ and $\mathrm{pH} 7.4$ at a temperature of $37^{\circ} \mathrm{C}$. An HPLC method was developed for quantification of the unchanged ester concentration.

Some of the esters (Gly-thiazole, Ala-thiazole-acyclovir, Leu-thiazole-acyclovir) were rather unstable, especially under acidic conditions, and underwent rapid hydrolysis into the chemical precursor acyclovir. At pH 7.4, the stability of Valthiazole-acyclovir was remarkable. At this $\mathrm{pH}$, Val-thiazole-acyclovir showed stability higher than that of valacyclovir (the first effective prodrug of acyclovir).
\end{abstract}

\section{Keywords}

Amino acids • Thiazole $•$ Antiviral drugs $•$ HPLC $\bullet$ Prodrugs

\section{Introduction}

The discovery of the guanine analogue of acyclovir (9-[(2-hydroxyethoxy)methyl]guanine), $A C V$, set the stage for a new generation of antiviral agents [1,2]. Along with its high specificity, ACV demonstrates low aqueous solubility and low bioavailability by oral administration (14\%). To overcome this problem, several acyclovir amino acid esters have been synthesised. Valaciclovir, the valine ester of ACV, was found to metabolise easily by oral administration and possess four-fold higher bioavailability than acyclovir [3-7]. 
Recently, we synthesised acyclovir esters with peptidomimetics and studied their antiviral activity against HSV-1 and HSV-2 [8-10].

Contrary to acyclovir esters with natural amino acids, the results showed that modification of acyclovir with thiazole, oxazole and thiazolyl-thiazole containing amino acids (Gly, Val, Ala, Leu) decreased the antiviral effect of acyclovir. The only exception with prominent activity against HSV-2 turned out to be the Ala-thiazolyl ester of acyclovir [8, 9]. The object of this study was to assess the chemical stability of some of the synthesised acyclovir esters with peptidomimetics at $\mathrm{pH} 1.0$ and $\mathrm{pH} 7.4$ at $37^{\circ} \mathrm{C}$. An HPLC method was used for quantification of the ester concentrations [11, 12].

\section{Results and Discussion}

The chemical stability of acyclovir esters: Boc-2-aminomethyl-thiazole-acyclovir (1), Boc-2Ala-thiazole-acyclovir (2), Boc-2-Val-thiazole-acyclovir (3) and Boc-2-Leu-thiazoleacyclovir (4) was studied under experimental conditions of biological relevance, i.e. at $\mathrm{pH} 1$ and $\mathrm{pH} 7.4$, at a temperature of $37^{\circ} \mathrm{C}$. The compounds were synthesised as previously described $[8,9]$. The structures of the compounds under investigation are presented in Fig. 1.<smiles>CC(NC(=O)OC(C)(C)C)c1nc(C(=O)OCCOCn2cnc3c(=O)[nH]c(N)nc32)cs1</smiles>

Boc-2-aminomethyl-thiazole-acyclovir (Boc-Gly-(Thz)-ACV)

Boc-2-Ala-thiazole-acyclovir

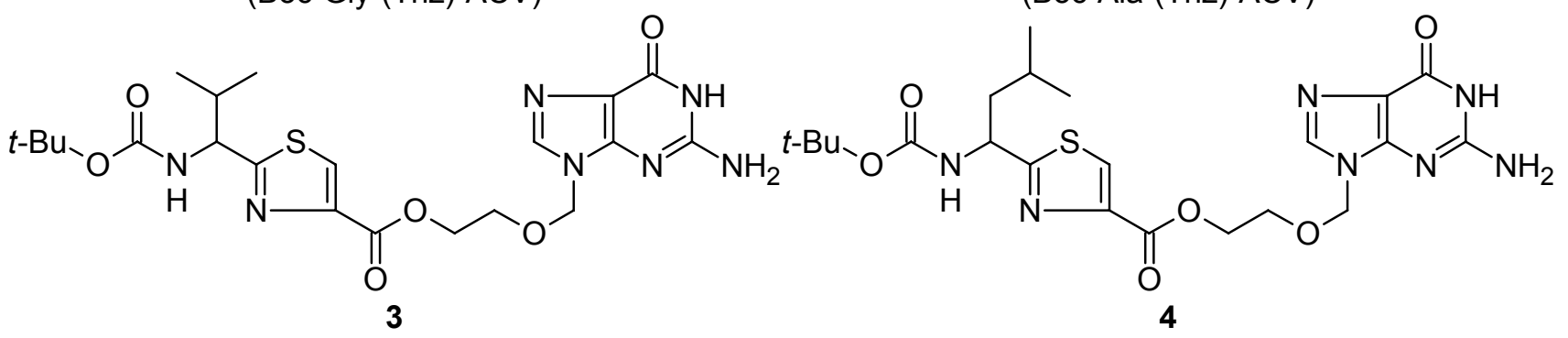

Boc-2-Val-thiazole-acyclovir

(Boc-Val-(Thz)-ACV)

Boc-2-Leu-thiazole-acyclovir

(Boc-Leu-(Thz)-ACV)

Fig. 1. Acyclovir esters with peptidomimetics.

It was established that, under the described experimental conditions, some esters underwent decomposition by hydrolysis. The hydrolysis followed apparent first order kinetics, and the rate constants $(K)$ were obtained as slopes from the semi-logarithmic plots of the unchanged ester concentration versus time. The chemical stability was assessed by means of the decomposition half-lives: 


$$
t_{1 / 2}=\ln \frac{2}{K}
$$

Tab. 1. The $t_{1 / 2}$ values of the examined compounds at $\mathrm{pH}=1$ and $\mathrm{pH}=7.4$

\begin{tabular}{|c|c|c|c|}
\hline № & Compound & $\mathrm{pH}=1, t_{1 / 2}, h$ & $\mathrm{pH}=7.4, t_{1 / 2}, \mathrm{~h}$ \\
\hline 1 & Boc-Gly(Thz)-ACV & $1.1 \pm 0.1$ & $5.9 \pm 0.5$ \\
\hline 2 & Boc-Ala(Thz)-ACV & $1.3 \pm 0.1$ & $7.8 \pm 0.5$ \\
\hline 3 & Boc-Val(Thz)-ACV & $0.7 \pm 0.1$ & $17.8 \pm 0.9$ \\
\hline 4 & Boc-Leu(Thz)-ACV & $2.6 \pm 0.2$ & $5.0 \pm 0.4$ \\
\hline
\end{tabular}

Chemical stability measurements revealed that the dipeptide prodrugs of acyclovir were relatively unstable at acidic $\mathrm{pH}$ (Tab. 1, Fig. 2). Under these conditions, all of the observed $t_{1 / 2}$ were less than $2.6 h$.

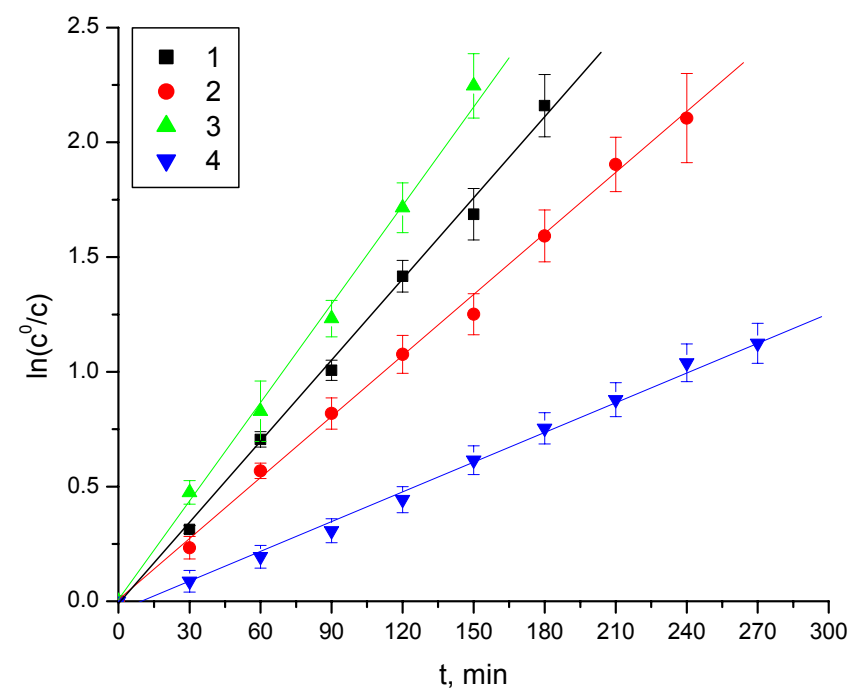

Fig. 2. Decrease of the concentration of the examined prodrugs at $\mathrm{pH} 1.0(\mathrm{HCl})$

At $\mathrm{pH}$ 7.4, the Boc-2-Val-thiazole-acyclovir (3) was more stable $\left(\mathrm{t}_{1 / 2}=17 \mathrm{~h}\right)$ than valacyclovir $\left(t_{1 / 2}=13 \mathrm{~h}\right)$ [3], the first effective prodrug of acyclovir, (Tab. 1, Fig. 3).

The Boc-2-Val-thiazole-acyclovir (3) and Boc-2-aminomethyl-thiazole-acyclovir (1) were less stable than the Boc-2-Ala-thiazole-acyclovir (2) and Boc-2-Leu-thiazole-acyclovir (4) at $\mathrm{pH}$ 1.0. The esters (1) and (4) manifested lower stability at $\mathrm{pH} 7.4$. It was found that the rest of compounds were stable at $\mathrm{pH} 7.4$. 


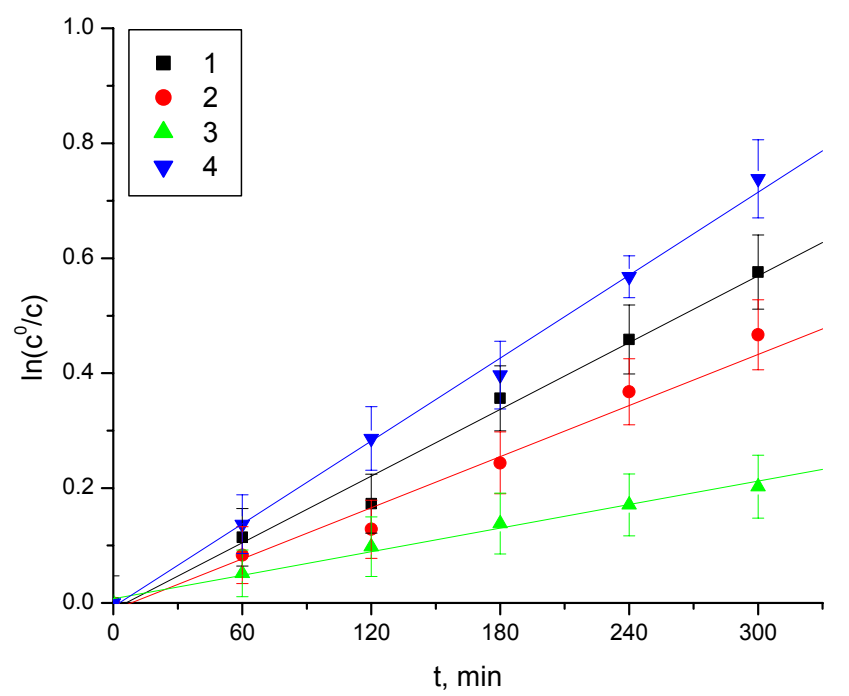

Fig. 3. Decrease of the concentration of the examined prodrugs in buffer solution at $\mathrm{pH}$ 7.4 (phosphate buffer)

\section{Experimental}

\section{Chemicals}

Acetonitrile for HPLC the buffer components $\mathrm{HCl}, \mathrm{Na}_{2} \mathrm{H}_{2} \mathrm{PO}_{4}$ of the purest grade, were purchased from Merck (Germany). The Grace Vidac chromatographic column was used (USA).

\section{Chromatography}

Chromatography was carried out isocratically, on a modular KNAUER HPLC system (Germany), consisting of a Smartline Pump 1000, a Smartline Manager 5000 solvent degasser, an injector with a $20 \mu \mathrm{l}$ loop and a Smartline UV Detector 2600 diode array. The analyses were controlled and the data were acquired with EuroChrom software. The mobile phase consisted of acetonitrile/water in a ratio of 30:70 or 50:50 v/v depending on the polarity of the compound and a flow rate $1 \mathrm{ml} / \mathrm{min}$ was used. The detection was performed at relevant $\lambda_{\max }$ for the respective compound (range 252-262 nm).

\section{Kinetic study}

A single chromatographic method was used to detect the studied acyclovir esters with thiazole rings containing amino acids (Gly, Ala, Val, Leu) in aqueous buffer solutions at $\mathrm{pH}$ $1.0(0.1 \mathrm{M} \mathrm{HCl})$ and $\mathrm{pH} 7.4$ (phosphate buffer). Twenty microlitres of each sample were injected into a reverse phase HPLC C18 column. The mobile phase consisted of acetonitrile/water at a ratio of $30: 70$ or $50: 50 \mathrm{v} / \mathrm{v}$ depending on the polarity of the compound. The analyses of the esters of acyclovir with amino acid (Gly, Ala, Val, Leu) containing thiazole rings were validated. The specificity of the method was investigated by observing potential interference between the esters of acyclovir and its parent drug, acyclovir. No interfering peaks were presented in the chromatograms. The linearity of the relationship between the peak area and concentration was determined by analysing six standard solutions in a concentration range of $0.1-1.0 \mathrm{mmol} / \mathrm{l}$. For all analytes, the relationship between the peak area ratio of the drug to the internal standard and 
concentration was linear over the entire examined concentration range. The correlation coefficients of the calibration curves were greater than 0.997 . For all of the examined compounds the coefficient of variation calculated for the six analysed samples did not exceed $5 \%$.

Hydrolysis of acyclovir esters with thiazole rings containing amino acids (Gly, Ala, Val, Leu) was studied at $\mathrm{pH} 1.0(\mathrm{HCl})$ and $\mathrm{pH} 7.4$ (phosphate buffered saline). Stock solutions of the prodrugs were prepared and used immediately for stability studies. Aliquots $(9.8 \mathrm{ml})$ of the buffer were placed in a screw-capped vial and allowed equilibrate at $37^{\circ} \mathrm{C}$. A prodrug stock solution $(0.2 \mathrm{ml})$ was added to the buffer. The vial was placed in a constant shaker bath set at $37^{\circ} \mathrm{C}$ and $60 \mathrm{rpm}$. Each sample was directly analysed by HPLC.

\section{Conclusion}

The chemical stability of acyclovir esters with peptidomimetics was studied under

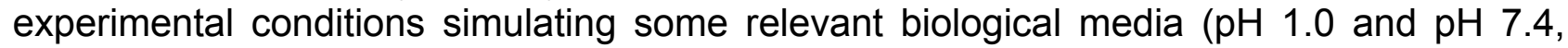
$37^{\circ} \mathrm{C}$ ). The examined compounds were not stable in acidic media. This result was predictable, because the compounds are esters and esters easily undergo decomposition by hydrolysis in acidic media. The order of decreasing stability in neutral media and at a temperature of $37^{\circ} \mathrm{C}$ was $3>>2>4>1$. Under the same conditions, the Boc-2-Val-thiazoleacyclovir (3) was more stable than valacyclovir $\left(t_{1 / 2}=13 \mathrm{~h}\right)$, the first effective prodrug of acyclovir [4]. Boc-2-Val-thiazole-acyclovir (3) exhibit the highest chemical stability at $\mathrm{pH} 7.4$ compared to the other examined compounds, but it did not exhibit a satisfying effect against HSV-1 or HSV-2 [5]. The compound Boc-2-Ala-thiazole-acyclovir (2) showed an appreciable effect against HSV-2 and exhibited satisfying chemical stability. The correlation with both biological activity and chemical stability suggests that the Boc-2-Alathiazole-acyclovir (2) could be attractive for antiviral chemotherapy.

\section{Acknowledgements}

We gratefully acknowledge financial support from the National Fund for Scientific Research of Bulgaria (VUL-304/07). The authors thank Dr. B. Radoev, Faculty of Chemistry, University of Sofia, Bulgaria and Prof. Dr. Tsenka Milkova, Chemistry

Department, South-West University, Blagoevgrad, Bulgaria for the helpful discussion.

\section{Authors' Statement}

\section{Competing Interests}

The authors declare no conflict of interest.

\section{References}

[1] Elion GB, Furman PA, Fyfe JA, de Miranda P, Beauchamp L, Schaeffer HJ.

Selectivity of action of an antiherpetic agent, 9-(2-hydroxyethoxymethyl)guanine.

Proc Nat Acad Sci USA. 1977; 74: 5716-5720.

doi:10.1073/pnas.74.12.5716 
[2] De Clercq E, Field HJ.

Antiviral prodrugs - the development of successful prodrug strategies for antiviral chemotherapy.

Br J Pharmacol. 2006; 147: 1-11.

doi:10.1038/sj.bjp.0706446

[3] Beauchamp LM, Orr GF, de Miranda P, Burnette T, Krenitsky TA.

Amino acid ester prodrugs of aciclovir.

Antivir Chem Chemother. 1992; 3: 157-164.

[4] Beauchamp LM, Krenitsky TA.

Acyclovir prodrugs: the road to valaciclovir.

Drugs Fut. 1993; 18: 619-628.

[5] Field HJ, De Clercq E.

Antiviral drugs - a short history of their discovery and development.

Microbiol Today. 2004; 31: 58-61.

[6] Anand BS, Nashed YN, Mitra AK.

Novel dipeptide prodrugs of acyclovir for ocular herpes infection: Bioreversion, antiviral activity and transport across rabbit cornea.

Curr Eye Res. 2003; 26: 151-163.

doi:10.1076/ceyr.26.3.151.14893

[7] Anand BS, Katragadda S, Nashed YE, Mitra AK.

Amino acid prodrugs of acyclovir as possible antiviral agents against ocular HSV-1 infection:

interaction with the neutral and cationic amino acid transporter on the cornel epithelium.

Curr Eye Res. 2004; 29: 153-166.

doi:10.1080/02713680490504614

[8] Stankova I, Dzimbova T, Shishkov St, Kostova K, Galabov A.

Synthesis and biological activity of amino acid ester prodrugs of acyclovir.

Rolka K, Rekowski P, Silberring J (editors).

Peptides 2006, Proceedings of the Twenty-Ninth European Peptide Symposium. 2007; 226-227.

[9] Stankova I, Dzimbova T, Shishkov S.

Synthesis and antiviral activity of some amino acid esters of acyclovir.

In: Escher E, Lubell WD, Del Valle S (editors).

Adv Exp Med Biology. 2007; 611: 169-170,

Peptides for Youth, Proceedings of te $20^{\text {th }}$ American Peptide Symposium.

doi:10.1007/978-0-387-73657-0_77

[10] Stankova I, Dzimbova T, Shishkov St, Todorov D, Galabov A.

Esters of Acyclovir with Peptidomimetics - Synthesis and Antiviral Activity.

in preparation

[11] Zacchigna M, Di Luca, Maurich GV, Boccu E.

Syntheses, chemical and enzymatic stability of new poly(ethyleneglycol)-acyclovir prodrugs.

Farmaco. 2002; 57: 207-214.

doi:10.1016/S0014-827X(01)01193-4

[12] Zhivkova Zv, Stankova I.

Stability of some novel thymidine, 5-bromo-2'-deoxyuridine and 3'-azido-2', 3'- dideoxythymidine analogues.

Int J Pharm. 2000; 200: 181-185.

doi:10.1016/S0378-5173(00)00367-7 